Hill, R. W., Huelsman, T. J., Furr, R. M., Kibler, J., Vicente, B. B., \& Kennedy, C. (2004). A new measure of perfectionism: The Perfectionism Inventory. Journal of Personality Assessment, 82(1): 80-91 (Feb 2004).

Published by Taylor \& Francis (ISSN: 0022-3891).

\title{
A New Measure of Perfectionism: The Perfectionism Inventory
}

Robert W. Hill, Timothy J. Huelsman, R. Michael Furr, Jason Kibler, Barbara B. Vicente, and Christopher Kennedy

\begin{abstract}
In this investigation, we produced a new 8-scale measure of perfectionism called the Perfectionism Inventory (PI) that is designed to capture the important constructs provided by 2 existing Multidimensional Perfectionism Scale (MPS; Frost, Marten, Lahart, \& Rosenblate, 1990; Hewitt \& Flett, 1991b) measures, along with new perfectionism scales. In the results from 3 studies, we describe scale development, scale psychometric properties, and criterion-related validity evidence for the 8 PI scales: Concern Over Mistakes, High Standards for Others, Need for Approval, Organization, Parental Pressure, Planfulness, Rumination, and Striving for Excellence. We present relationships between the 8 PI scales, relevant MPS scales, and other criterion measures. Second-order exploratory and confirmatory analyses provide support for the 8-scale PI model as well as support for 2 composite PI factors labeled Conscientious Perfectionism and Self-Evaluative Perfectionism.
\end{abstract}


Research on perfectionism has evolved from an initial presentation of a unidimensional construct (Burns, 1980) to the development of several independent multidimensional conceptualizations of perfectionism (Frost, Marten, Lahart, \& Rosenblate, 1990; Hewitt \& Flett, 1991b; Johnson \& Slaney, 1996; Rheaume, Freestone, Dugas, Letarte, \& Ladouceur, 1995). Over the last dozen years, many investigators have utilized either the Multidimensional Perfectionism Scale (MPS) developed by Hewitt and Flett (MPS-HF; 1991b) or the measure by the same name developed by Frost et al. (MPS-F; 1990). Other more recent measures of perfectionism, such as the Almost Perfect Scale (Johnson \& Slaney, 1996; Slaney, Rice, Mobley, Trippi, \& Ashby, 2001) or an experimental model proposed by Rheaume, Freeston, et al. (1995) have less cumulative psychometric support relative to the numerous investigations using the MPS scales. The MPS-HF and the MPS-F provide notably different approaches to measuring perfectionism so that investigators have variously reported associations between either a three-scale model (in the case of the MPS-HF) or a six-scale model (in the case of the MPS-F) and numerous other personality constructs and indexes of psychological distress (for a summary, see Shafran \& Mansell, 2001).

These two predominant multidimensional measures of perfectionism have some conceptual overlap, but each also offers unique factors (Frost, Heimberg, Holt, Mattia, \& Neubauer, 1993), making the choice of a preferred instrument for assessing perfectionism unclear. Currently, an investigator would need to use both MPS measures to assess the full range of fundamental perfectionism constructs (e.g., Antony, Purdon, Huta, \& Swinson, 1998; Bastiani, Rao, Weltzin, \& Kaye, 1995; Enns \& Cox, 1999; Flett, Sawatzky, \& Hewitt, 1995; Nilsson, Paul, Lupini, \& Tatem, 1999; Purdon, Antony, \& Swinson, 1999). However, the use of the combined nine scales from the two MPS measures is relatively inefficient given the overlapping constructs and significant redundancy among the scales (correlations among the subscales from the two scales correlate as high as .70; see Enns \& Cox, 2002).

The MPS-HF (Hewitt\&Flett, 1991b) assesses perfectionism as a three-dimensional construct composed of self-oriented perfectionism (SOP), other-oriented perfectionism (OOP), and socially prescribed perfectionism (SPP).SOP reflects the tendency to set unrealistic standards for oneself and to focus on flaws or failures in performance in conjunction with strong self-scrutiny (Hewitt\&Flett, 1991b).SOPis closest to the construct most often referred to as perfectionism by investigators attempting to define the construct (Blatt, 1995; Burns, 1980; Hewitt, Mittelstaedt, \& Wollert, 1989; Shafran 
\&Mansell, 2001).OOPreflects the tendency to have exaggerated expectations of others and to evaluate others critically. SPP reflects the perceived need to attain standards and expectations prescribed by significant others to win approval (Hewitt\& Flett, 1991b). Hewitt, Flett, and many other investigators (e.g., Flett, Hewitt, Blankstein,\&Gray, 1998; Flett, Hewitt,\& Derosa, 1996; Flett, Hewitt, Endler,\&Tassone, 1995; Hewitt \& Flett, 1991a, 1991b; Hewitt, Flett, \& Turnull-Donovan, 1992; Hewitt, Flett, Turnbull-Donovan,\&Mikail, 1991; Hill, Zrull, \& Turlington, 1997) have described associations between these three interpersonally oriented scales and diverse personality constructs and behaviors, providing support for the criterion-related validity and construct validity of these three dimensions.

Independent of Hewitt and Flett (1991b), Frost et al. (1990) developed a perfectionism measure with six subscales including Concern Over Mistakes (CM), Personal Standards (PS), Parental Expectations (PE), Parental Criticism (PC), Doubts About Actions (DA), and Organization (OR). The $\mathrm{CM}$ subscale reflects negative reactions to mistakes, a tendency to interpret mistakes as failures, and the belief that failure inevitably results in a loss of respect from others (Flett, Sawatzky, et al., 1995). PS reflects high standards of performance and the tendency to evaluate oneself based on performance. $P E$ and $P C$ reflect the extent to which parents are perceived as having high expectations and the extent to which parents are perceived as being overly critical. DA reflects a mix of concern about doing things right, repeating work, and getting behind. OR reflects neatness and organization. Frost and others (e.g., Frost et al., 1990; Frost et al., 1995; Frost \& Steketee, 1997) have described the associations between the MPS-F subscales and diverse personality constructs and behaviors, providing support for the convergent and discriminant validity of the instrument. Factor analytic investigations of the MPS-F have suggested that the six scales might instead be more parsimoniously reduced to three, four, or five scales (Cox, Enns, \& Clara, 2002; Purdon et al., 1999; Stober, 1998; Stumpf \& Parker, 2000).

Although the two MPS measures assess some apparently distinct dimensions of perfectionism, some research reveals points of overlap. For example, correlational analyses indicated MPS-HF SOP and OOP were most strongly associated with MPS-F CM and PS subscales compared with more modest correlations with the other MPS-F subscales (Flett, Sawatzky, et al., 1995). MPS-HF SPP was most strongly associated with MPS-F CM, PE and PC, and DA (for a summary of MPS correlations, see Enns \& Cox, 2002). The MPS-HF and the MPS-F both have constructs related to high personal standards, concern about the approval of others 
regarding performance, and finding fault with oneself. A more recent investigation (Cox et al., 2002) used item loadings from exploratory factor analyses to develop briefer versions of the MPS-HF (reducing the three scales from 45 to 15 items) and the MPS-F (reducing the six scales of 35 items to 5 scales with 22 items) and thus improved factor model fit indexes using confirmatory factor analyses. The MPS-HF scales appear to include unnecessary or redundant items, the MPS-F includes some items that load on more than one scale, and some MPS-F scales could be effectively combined. We propose that a single measure capturing the fundamental MPS perfectionism constructs would be useful for researchers who desire a comprehensive measure of perfectionism.

In this investigation, we describe the development of a new measure of perfectionism as an alternative to the two widely used MPS measures. Currently, an assessment of the full range of perfectionism requires an investigator use both MPS measures. Failure to do so risks omitting some potentially relevant facets of perfectionism. The MPS-HF provides a limited three-scale interpersonal interpretation of perfectionism without the capacity to distinguish specific relevant facets such as organization, concern about mistakes, planfulness, obsessive thinking, and parental expectations. The MPS-F provides a more diverse set of subscales but omits the perfectionistic concern for the standards of others as well as planfulness, and some of the six scales are redundant with each other. In the following investigation, we describe the development of the Personality Inventory $(\mathrm{PI})$ and support for its reliability and validity.

When reviewing the literature on measuring perfectionism, six of the constructs assessed by MPS scales and other perfectionism measures appeared worthy of inclusion in a new measure. These new scales were labeled Striving for Excellence (e.g., Burns, 1980; MPS-F PS, MPS-HF SOP), Concern Over Mistakes (e.g. MPS-F CM), High Standards for Others (e.g. MPS-HF OOP), Need for Approval (for perfectionistic performance, e.g., MPS-F DA, MPS-HF SPP), Organization (e.g., MPS-F OR), Perceived Parental Pressure (e.g., MPS-F PC, PE; see also Kawamura, Frost, \& Harmatz, 2002) and Rumination. Research on perfectionism has repeatedly revealed a strong positive relationship between perfectionism and obsessive-compulsive rumination symptoms (Antony et al., 1998; Bouchard, Rheaume, \& Ladouceur, 1999; Frost \& Steketee, 1997; Kawamura, Hunt, Frost, \& Dibartolo, 2001; Rheaume, Freestone, et al., 2000; Rheaume, Ladouceur, \& Freeston, 1995, 2000), suggesting the development of items to assess rumination about past errors, less than perfect performance, or future problems. 
A pilot pool of items to assess these constructs was administered to a sample of 382 undergraduates and exploratory factor analyses produced the scales just mentioned along with a set of items that reflected Planfulness, a tendency to plan ahead thoughtfully and deliberately before making decisions (Kennedy, 2001). The Planfulness items were included in subsequent PI revision, as this construct describing the tendency to carefully think ahead rather than act impulsively defined a cohesive construct strongly associated with other perfectionism scales.

In this investigation, we describe the subsequent revision of the eight PI scales and the administration of the item pool to two samples in which exploratory principal components analyses were used to refine the scales and structural equation modeling was used to confirm the measurement model. Both test-retest reliability and internal consistency reliability were assessed as well as comparisons between the PI and the MPS scales and other criterion measures.

In addition to creating a new measure of perfectionism, we were also interested in evidence for categorizing perfectionism into 2 second-order composite factors comprised of positive or "adaptive" dimensions versus negative or "maladaptive" dimensions of perfectionism as described by previous investigators (Cox et al., 2002; Frost et al., 1993; Hamachek, 1978; Kawamura et al., 2001; Rheaume, Freeston, et al., 2000; Rice, Ashby, \& Slaney, 1998; Rice \& Mirzadeh, 2000; Slade \& Owens, 1998; Slaney et al., 2001; Stumpf \& Parker, 2000). Factor analyses of the MPS and other perfectionism measures have described variously labeled positive and negative perfectionism factors, such as the "positive striving" and "maladaptive evaluative concerns" factors described by Frost et al. (1993), along with some associations with other variables (for summaries, see Enns \& Cox, 2002, and Shafran \& Mansell, 2001). We conducted second order exploratory and confirmatory analyses of the new perfectionism scales to assess support for distinguishable clusters of perfectionism constructs.

In summary, this investigation was designed to construct a newmeasure of perfectionism to accomplish several goals: (a) to create a more conceptually comprehensive instrument, combining the significant perfectionism constructs currently spread across the two MPS measures into one measure; (b) to include the measurement of additional perfectionism constructs not described by eitherMPSmeasure (i.e., Planfulness and Rumination); and (c) to explore higher order perfectionism factors suggested by previous perfectionism research. 


\section{STUDY 1: EXPLORATORY ANALYSES}

BY SCALE

In this investigation, we proceeded to refine PI factors using exploratory analyses on the pilot scales supplemented with additional items created by us.

\section{Method}

\section{Participants and Procedure}

The revised $\mathrm{PI}$ item pool (131 items) was administered to a sample of 250 undergraduate students $(M=18.9$ years, $S D$ $=2.6$; $63 \%$ women, $28 \%$ men, $9 \%$ missing sex; $93 \%$ White, $7 \%$ African American or other race). From this sample, 82 participants (63 women, 19 men) completed a retest of the initial item pool after a 3- to 6-week interval to assess stability over time.

\section{PI Revised Item Pool}

Items for each of the eight PI scales were created by three of the authors (Hill, Kibler, Vicente) with an emphasis on avoiding ambiguity in item content and minimizing content overlap with other scale constructs. The item format included five possible responses from strongly disagree to strongly agree. After developing a large pool of items (12 to 36 items per scale), including items from the pilot analyses, each item was rated for content relevance and quality using a 3-point ordinal scale with $1=$ unacceptable, $2=$ fair, and $3=$ good by the three authors who wrote the items. Items receiving cumulative ratings of 8 or 9 across the three raters were retained, resulting in 15 to 18 items per scale (for a total of 131 items).

\section{Results}

\section{Exploratory Analysis of PI Scales}

Separate principal components analyses were performed for each of the eight item pools. In each analysis, we forced one-component solutions, and items with a loading of .63 or greater (considered "good" by Comrey\&Lee, 1992) were retained, reducing the total number of $\mathrm{PI}$ items from 131 to 70.

The scales were further refined based on more focused content analyses (e.g., removal of items whose content overlapped in the judgment of the authors), changes in coefficient alpha with item deleted (i.e., if alpha increased by .10 or greater, the item 
was dropped), and items with small variances (i.e., if the variance was less than .80). These considerations resulted in the deletion of an additional 11 items, producing a 59-item instrument. The results of principal components analyses for the final item set for each scale are reported in Table 1 . This table also presents eigenvalue ratios for the first and second components extracted for each PI scale and the variance accounted for by the first component. As Table 1 reveals, each scale has a strong unidimensional structure.

TABLE 1

Results of Principal Components Analysis for Final Perfectionism Inventory Scales

\begin{tabular}{lccc}
\hline & & $\begin{array}{c}\text { Eigenvalue } \\
\text { Component } 1 \\
\text { /Eigenvalue } \\
\text { Component } 2\end{array}$ & $\begin{array}{c}\text { Variance } \\
\text { Accounted for } \\
\text { by Component } \\
\text { I(\%) }\end{array}$ \\
\hline Scale & $\begin{array}{c}\text { No. of } \\
\text { Items }\end{array}$ & $3.882 / .952$ & 48.53 \\
\hline $\begin{array}{l}\text { Concern Over } \\
\quad \text { Mistakes }\end{array}$ & 8 & $3.693 / .688$ & 52.76 \\
$\begin{array}{l}\text { High Standards for } \\
\quad \text { Others }\end{array}$ & 7 & $4.446 / .681$ & 55.58 \\
$\begin{array}{l}\text { Need for Approval } \\
\text { Organization }\end{array}$ & 8 & $4.811 / .690$ & 60.14 \\
$\begin{array}{l}\text { Perceived Parental } \\
\quad \text { Pressure }\end{array}$ & 8 & $4.589 / .941$ & 57.37 \\
$\begin{array}{l}\text { Planfulness } \\
\text { Rumination }\end{array}$ & 8 & $3.854 / .699$ & 55.06 \\
Striving for & 7 & $3.816 / .759$ & 54.52 \\
$\quad$ Excellence & 7 & $3.425 / .652$ & 57.09 \\
\hline
\end{tabular}

Means, standard deviations, correlations among the scales, Cronbach's coefficient alphas, and test-retest correlations are reported in Table 2 . These analyses resulted in an eight-scale measure of perfectionism comprising 59 items, with coefficient alphas ranging from .83 to .91. Test-retest correlations for the eight PI scales ranged from .71 to .91 over a 3- to 6 -week interval ( $M$ interval was 4.5 weeks). See Table 3 for scale descriptions, sample items, and expected associations with MPS scales.

Independent sample $t$ tests identified statistically significant differences between men and women on seven of the eight perfectionism scales (all except Striving for Excellence), but the mean difference was only .18, with women scoring higher than men on four scales and men scoring higher than women on three scales. In addition, the mean effect size $(d)$ for these differences was small, ranging from .037 to .345 ( $M d=$ .237).Dueto the small size of these gender differences, no further analyses by gender were conducted. 
TABLE 2

Means, Standard Deviations, Correlations Among Scales, Cronbach's Coefficient Alpha, and Test-Retest Correlations for PI Scales

\begin{tabular}{|c|c|c|c|c|c|c|c|c|c|c|c|c|}
\hline Scale & $\begin{array}{l}\text { No. of } \\
\text { Items }\end{array}$ & 1 & 2 & 3 & 4 & 5 & 6 & 7 & 8 & 9 & 10 & 11 \\
\hline 1. Concern Over Mistakes & 8 & 86 & & & & & & & & & & \\
\hline 2. High Standards for Others & 7 & .52 & $\underline{.83}$ & & & & & & & & & \\
\hline 3. Need for Approval & 8 & .63 & $\overline{.25}$ & .87 & & & & & & & & \\
\hline 4. Organization & 8 & $.18^{*}$ & .42 & $.18 *$ & .91 & & & & & & & \\
\hline 5. Perceived Parental Pressure & 8 & .33 & .30 & $.19^{*}$ & $.19^{*}$ & .88 & & & & & & \\
\hline 6. Planfulness & 7 & .27 & .29 & .35 & .49 & $.17^{*}$ & .86 & & & & & \\
\hline 7. Rumination & 7 & .73 & .47 & .67 & .38 & .34 & .43 & .87 & & & & \\
\hline 8. Striving for Excellence & 6 & .46 & .49 & .33 & .59 & .31 & .39 & $\overline{.52}$ & .85 & & & \\
\hline 9. Conscientious Perfectionism & & .46 & .70 & .38 & .81 & 30 & .72 & .57 & .80 & .75 & & \\
\hline 10. Self-Evaluative Perfectionism & & .86 & .48 & .82 & .25 & .59 & .39 & .87 & .55 & $\overline{.54}$ & 79 & \\
\hline 11. PI Composite & & .76 & .66 & 69 & .59 & .51 & .62 & .83 & .77 & .87 & .89 & 83 \\
\hline Scale $M$ & & 2.46 & 2.83 & 3.22 & 3.50 & 3.17 & 3.40 & 2.83 & 3.10 & 12.83 & 11.68 & 24.51 \\
\hline Scale $S D$ & & .75 & .78 & .77 & .86 & .89 & .76 & .82 & .80 & 2.41 & 2.61 & 4.40 \\
\hline Test-retest correlation & & .80 & .71 & .89 & .91 & .89 & .75 & .81 & .80 & .89 & .89 & .89 \\
\hline
\end{tabular}

Note. Cronbach's coefficient alpha is entered on the main diagonal and underlined. PI = Perfectionism Inventory.

For all correlations, $p<.001$, except $* p<.01$.

TABLE 3

Perfectionism Inventory Scales, Construct Definitions, Sample Items, and Expected Relationships With MPS Scales

\begin{tabular}{|c|c|c|c|c|}
\hline \multirow{2}{*}{$\begin{array}{l}\text { Perfectionism } \\
\text { Indicator Scale }\end{array}$} & \multirow[b]{2}{*}{ Construct Definition } & \multirow[b]{2}{*}{ Sample Item } & \multicolumn{2}{|c|}{$\begin{array}{l}\text { Strongest Expected } \\
\text { Relationships } \\
\text { With MPS Scales }\end{array}$} \\
\hline & & & $M P S-F$ & MPS-HF \\
\hline $\begin{array}{l}\text { Concern Over } \\
\text { Mistakes }\end{array}$ & $\begin{array}{l}\text { Tendency to experience distress or anxiety over } \\
\text { making a mistake }\end{array}$ & "I am particularly embarrassed by failure" & $\mathrm{CM}$ & - \\
\hline $\begin{array}{l}\text { High Standards for } \\
\text { Others }\end{array}$ & $\begin{array}{l}\text { Tendency to hold others to one's own perfectionist } \\
\text { ideals }\end{array}$ & $\begin{array}{l}\text { "I get upset when other people do not } \\
\text { maintain the same standards I do" }\end{array}$ & - & OOP \\
\hline Need for Approval & $\begin{array}{l}\text { Tendency to seek validation from others and to be } \\
\text { sensitive to criticism }\end{array}$ & $\begin{array}{l}\text { "I compare my work to others and often } \\
\text { feel inadequate" }\end{array}$ & $\mathrm{CM}, \mathrm{DA}$ & SPP \\
\hline Organization & Tendency to be neat and orderly & $\begin{array}{l}\text { "I always like to be organized and } \\
\text { disciplined" }\end{array}$ & OR & - \\
\hline $\begin{array}{l}\text { Perceived Parental } \\
\text { Pressure }\end{array}$ & $\begin{array}{l}\text { Tendency to feel the need to perform perfectly to } \\
\text { obtain parental approval }\end{array}$ & "My parent(s) hold me to high standards" & $\mathrm{PC}, \mathrm{PE}$ & - \\
\hline Planfulness & $\begin{array}{l}\text { Tendency to plan ahead and to deliberate over } \\
\text { decisions }\end{array}$ & $\begin{array}{l}\text { "I tend to deliberate before making up my } \\
\text { mind" }\end{array}$ & - & - \\
\hline Rumination & $\begin{array}{l}\text { Tendency to obsessively worry about past errors, } \\
\text { less than perfect performance, or future mistakes }\end{array}$ & $\begin{array}{l}\text { "I spend a lot of time worrying about } \\
\text { things I've done, or things I need to do" }\end{array}$ & $\mathrm{CM}, \mathrm{DA}$ & - \\
\hline $\begin{array}{l}\text { Striving for } \\
\text { Excellence }\end{array}$ & $\begin{array}{l}\text { Tendency to pursue perfect results and high } \\
\text { standards }\end{array}$ & $\begin{array}{l}\text { "I drive myself rigorously to achieve high } \\
\text { standards" }\end{array}$ & PS & SOP \\
\hline
\end{tabular}

\section{Exploratory Analysis of Higher Order Structure}

To examine the higher order structure of the $\mathrm{PI}$, an exploratory principal components analysis was performed using the exploratory sample. In our initial evaluation of this analysis, we examined the first component (eigenvalue $=3.79$, accounting for $47.37 \%$ of total variance). As shown in Table 4 , most of the scales loaded quite strongly on the component. The single exception was Perceived Parental Pressure, which had a lower loading than the other scales (.46). 
TABLE 4

Component Loadings From Second-Order

Exploratory Principle Components Analysis

of Perfectionism Inventory Scales

\begin{tabular}{|c|c|c|c|}
\hline \multirow{2}{*}{$\begin{array}{l}\text { Perfectionism } \\
\text { Inventory Scale }\end{array}$} & \multirow{2}{*}{$\begin{array}{c}\begin{array}{c}\text { One-Component } \\
\text { Extraction }\end{array} \\
\text { Component }\end{array}$} & \multicolumn{2}{|c|}{ Two-Component Extraction } \\
\hline & & Component 1 & Component 2 \\
\hline Organization & .60 & .99 & -.23 \\
\hline \multicolumn{4}{|l|}{ Striving for } \\
\hline Excellence & .75 & 70 & .20 \\
\hline Planfulness & .60 & 67 & .05 \\
\hline \multicolumn{4}{|l|}{ High Standards for } \\
\hline Others & .68 & $\underline{.49}$ & .31 \\
\hline Concern Over & & .07 & \\
\hline Mistakes & .78 & & .93 \\
\hline Need for Approval & 69 & -.13 & .89 \\
\hline Rumination & .86 & .17 & .80 \\
\hline \multicolumn{4}{|l|}{ Perceived Parental } \\
\hline Pressure & .46 & .15 & $\underline{38}$ \\
\hline
\end{tabular}

To evaluate the possibility that some facets of perfectionism are adaptive, whereas others are maladaptive (e.g., Frost et al., 1993), we examined the first and second rotated components of the principal components analysis. As shown in Table 4, the promax rotated solution resulted in a Conscientious Perfectionism component with strong loadings for Organization, Striving for Excellence, and Planfulness and a Self-Evaluative Perfectionism component with strong loadings for Concern Over Mistakes, Need for Approval, and Rumination. High Standards for Others loaded more strongly on Conscientious Perfectionism than on Self-Evaluative Perfectionism but not as strongly as did the other three PI scales. Perceived Parental Pressure loaded more strongly on Self-Evaluative Perfectionism than on Conscientious Perfectionism but not as strongly as did the other three PI scales.

Composite scores for Conscientious Perfectionism and Self-Evaluative Perfectionism were calculated by summing respective scale scores, and a PI composite score was calculated by summing all eight PI scale scores.

\section{Discussion}

These data provide support for the internal consistency and stability of the PI, an empirically derived self-report measure 
of perfectionism. The PI comprises 59 items distributed on eight scales with coefficient alphas ranging from .83 to .91. After item pool revision and evaluation, the eight scales demonstrated strong internal consistency, good variability, and moderate (expected) associations with each other. Test-retest reliability coefficients indicate good stability over a 1-month interval. Some modest gender differences on the eight scales were observed.

\section{STUDY TWO: CONFIRMATORY ANALYSES}

To further assess the psychometric properties of the PI scales, confirmatory analyses were performed with a new sample.

\section{Method}

\section{Participants and Procedure}

The revised $\mathrm{PI}$ item pool and criterion measures were administered to a sample of 366 undergraduate students $(M=$ 20.2 years. $S D=1.6 ; 62 \%$ women, $30 \%$ men, $8 \%$ missing sex; $96 \%$ White, $4 \%$ African American or other race).

\section{Results}

\section{Confirmatory Analysis of PI Scales}

To further evaluate the internal structures of the eight PI scales, a series of confirmatory factor analyses were performed (usingEQSVersion 5.7b; Benton\&Wu, 1995). Table 5reports the fit indexes and the range of factor loadings associated with unidimensional models for each scale, revealing generally strong unidimensional structures. Meeting the cutoffs for fit indexes suggested by $\mathrm{Hu}$ and Bentler (1999), the Tucker-Lewis index (TLI; also referred to as the nonnormed fit index) and comparative fit index (CFI) are both above .95 and the standardized root mean squared residual (SRMR) is below .04 for all scales except Concern Over Mistakes and Perceived Parental Pressure. These two scales did show acceptable fit to a unidimensional model, and the fit indexes were improved even more after freeing one parameter (correlation between two error variances) for each scale. 
TABLE 5

Fit Indexes and Factor Loadings of Unidimensional Confirmatory Factor Analysis Models of PI Subscales

\begin{tabular}{lcccccc}
\hline PI Scale & $\chi^{2}$ & $d f$ & TLI & CFI & SRMR & Loadings \\
\hline Concern Over Mistakes & 111.36 & 20 & .89 & .92 & .050 & .64 to .71 \\
High Standards for Others & 35.28 & 14 & .95 & .97 & .973 & .67 to .93 \\
Need for Approval & 50.57 & 20 & .96 & .96 & .037 & .53 to .81 \\
Organization & 69.58 & 20 & .96 & .97 & .032 & .55 to .72 \\
Perceived Parental Pressure & 147.59 & 20 & .86 & .90 & .060 & .62 to 80 \\
Planfulness & 22.85 & 14 & .99 & .99 & .025 & .58 to .75 \\
Rumination & 28.48 & 14 & .98 & .99 & .027 & .64 to 84 \\
Striving for Excellence & 30.10 & 9 & .96 & .97 & .031 & .50 to .78 \\
\hline
\end{tabular}

Note. $\mathrm{PI}=$ Perfectionism Inventory $; \mathrm{TLI}=$ Tucker-Lewis index; $\mathrm{CFI}=$ comparative fit index; $\mathrm{SRMR}=$ standardized root mean squared residual.

\section{Confirmatory Analysis of Higher Order Structure}

To further explore the relationships among the PI subscales, two structural models were examined paralleling the exploratory analyses. Using the confirmatory sample, we evaluated a one-factor "General Perfectionism" model and then a two-factor "Conscientious Perfectionism" and "Self-Evaluative Perfectionism" model. To identify the models, Organization, Striving for Excellence, Planfulness, and High Standards for Others were allowed to load on one factor, and Concern Over Mistakes, Need for Approval, Perceived Parental Pressure, and Rumination were allowed to load on another. 


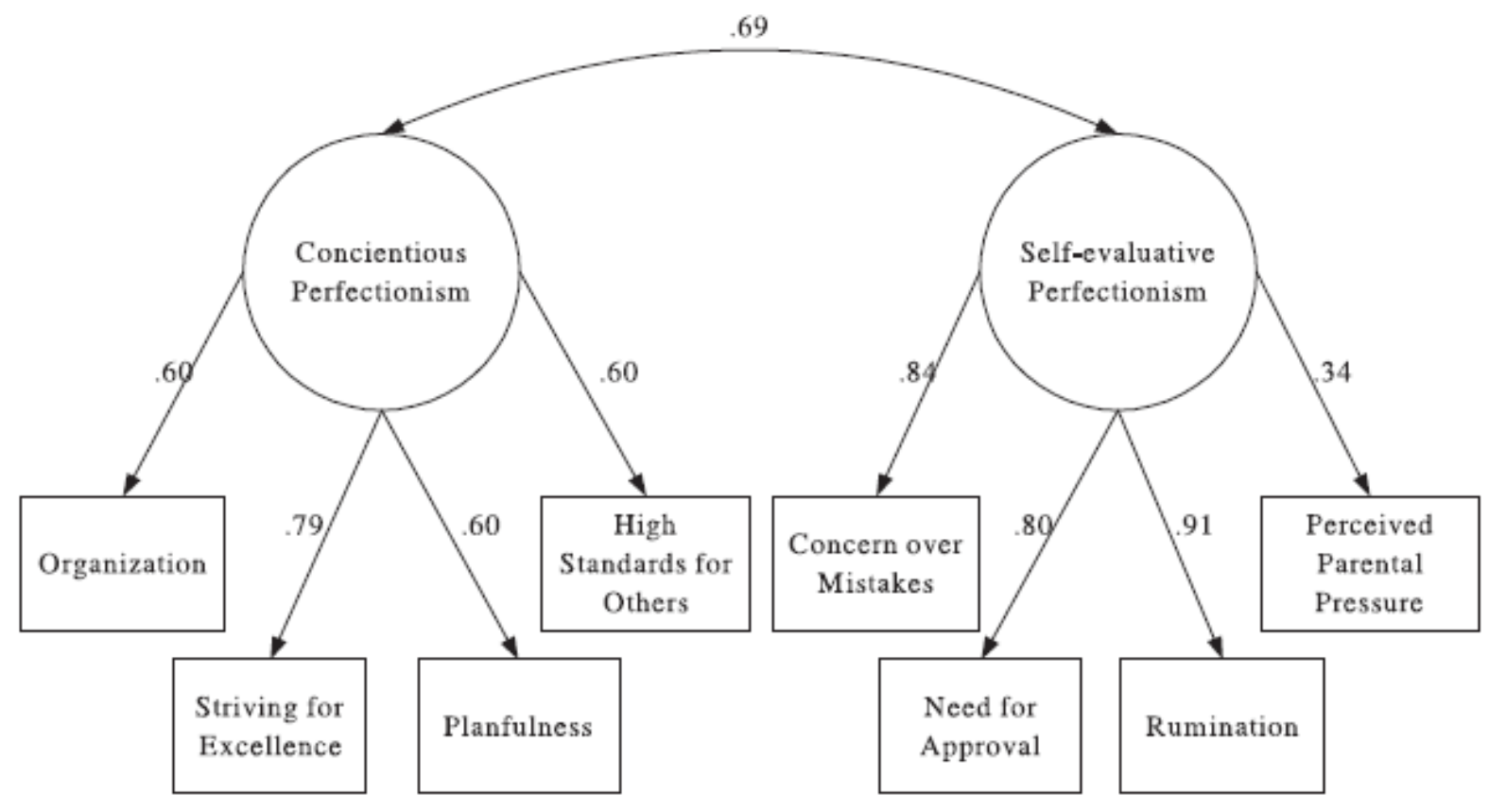

FIGURE 1 A two-factor higher order model of perfectionism.

For the one-factor model, the correlation between the two factors was fixed to unity. Although the factor loadings in this model were generally high (median loading $=.72$, range $=.32$ to .89) and Cronbach's alpha is acceptable $(\alpha=.83)$, this model did not provide strong overall fit to the data, $X 2(20, N=$ $366)=308.30, p<.001 ; \mathrm{TLI}=.68 ; \mathrm{CFI}=.77$; andSRMR $=.24$.

For the two-factor model, the correlation between the two factors was freely estimated (see Figure 1). Factor loadings were generally high (see Figure 1), and Cronbach's alphas were acceptable for both the Conscientious Perfectionism composite $(\alpha=.74)$ and the Self-Evaluative Perfectionism composite $(\alpha=.79)$. The two-factor model fit the data better than did the one-factor model, $X 2(1, N=366)=308.3-171.96$ $=136.91, p<.001$, with the two-factor model providing moderately acceptable overall fit to the data, $X 2(19, N=366)=$ $171.96, p<.001 ; \mathrm{TLI}=.82 ; \mathrm{CFI}=.88$; and SRMR $=.081$.

\section{Discussion}

In Study 2, confirmatory factor analysis was used to examine the structure of the eight PI scales as well as the higher order structure among the eight scales. Each of the eight scales showed clear unidimensional structures. The higher order analyses revealed a modest fit to a one-factor model but stronger support for a two-factor Conscientious Perfectionism and Self-Evaluative Perfectionism model. The 
two-factor, higher order structure provides support for previous research describing adaptive and maladaptive dimensions of perfectionism (e.g., Cox et al., 2002; Frost et al., 1993).

\section{STUDY 3: CONVERGENT VALIDITY WITH CRITERION MEASURES}

Associations with criterion measures were next assessed to further document PI validity evidence. In addition, we compared the predictive power of the MPS and PI scales for criterion measures using hierarchical regression analyses.

TABLE 6

Correlations Between Perfectionism Inventory Scales and Related Measures

\begin{tabular}{|c|c|c|c|c|c|c|c|c|c|c|c|}
\hline Scale & $C M$ & $H S$ & $N A$ & $O R$ & $p P$ & $P L$ & $R U$ & $S E$ & $C P$ & SEP & $P L-C$ \\
\hline \multicolumn{12}{|l|}{ Perfectionism: MPS-Fa } \\
\hline Concern Over Mistakes & .82 & .43 & .58 & .18 & .38 & .30 & .70 & .52 & .47 & .78 & .72 \\
\hline Doubts About Actions & .63 & .37 & .60 & .24 & .20 & .38 & .70 & .43 & .47 & .67 & .65 \\
\hline Parental Criticism & .41 & .25 & .20 & $-.03^{n s}$ & .60 & $.02^{n s}$ & .32 & .17 & .14 & .49 & .36 \\
\hline Parental Expectations & .31 & .27 & .18 & $.07^{n s}$ & .85 & $.06^{n s}$ & .29 & .32 & .23 & .53 & .43 \\
\hline Personal Standards & .47 & .50 & .36 & .45 & .39 & .44 & .52 & .72 & .70 & .55 & .71 \\
\hline Organization & .12 & .36 & .18 & .89 & $.11^{* *}$ & .49 & .31 & .51 & .76 & .23 & .55 \\
\hline \multicolumn{12}{|l|}{ Perfectionism: MPS-HF ${ }^{b}$} \\
\hline Self-Oriented & .47 & .42 & .34 & .47 & .42 & .45 & .55 & .79 & .71 & .57 & .73 \\
\hline Other-Oriented & .33 & .62 & $.14^{* *}$ & .29 & .30 & .26 & .37 & .42 & .53 & .36 & .51 \\
\hline Socially-Prescribed & .65 & .35 & .49 & $.16^{* *}$ & .58 & .21 & .61 & .42 & .38 & .74 & .65 \\
\hline \multicolumn{12}{|l|}{ Symptoms: BSI ${ }^{\mathrm{c}}$} \\
\hline Somatic Complaints & .35 & $.14^{*}$ & 31 & $.13^{*}$ & $.11^{*}$ & $.13^{*}$ & .34 & .17 & .19 & .35 & .31 \\
\hline Depression & .46 & $.16^{* *}$ & .46 & $.03^{n s}$ & $.15^{* *}$ & .18 & .46 & $.13^{*}$ & .17 & .49 & 39 \\
\hline Obsessive_Compulsive & .40 & $.14^{* *}$ & .46 & $.08^{\text {ns }}$ & $.10^{*}$ & .19 & .46 & .18 & .19 & .45 & .37 \\
\hline Anxiety & .42 & .28 & .42 & .22 & .25 & .25 & .49 & .29 & .35 & .50 & .49 \\
\hline Interpersonal Sensitivity & .52 & .18 & .68 & .17 & $.13^{*}$ & .22 & .56 & .27 & .28 & .60 & .51 \\
\hline Hostility & .41 & .30 & .31 & $.10^{*}$ & .21 & $.05^{n s}$ & .39 & $.15^{* *}$ & .20 & .42 & .36 \\
\hline Phobic Anxiety & .39 & $.14^{* *}$ & .39 & $.13^{*}$ & $.15^{* *}$ & $.13^{*}$ & .39 & $.15^{* *}$ & .21 & .42 & .37 \\
\hline Paranoia & .48 & .28 & .49 & .18 & .21 & .21 & .54 & .30 & .33 & .55 & .51 \\
\hline Psychoticism & .49 & .19 & .48 & $.09 n s$ & $.16^{* *}$ & .19 & .49 & .17 & .22 & .51 & .43 \\
\hline Global Severity Index & .54 & .24 & .55 & .16 & .20 & .21 & .57 & .25 & .29 & .59 & .51 \\
\hline \multicolumn{12}{|c|}{ Obsessive-Compulsive Inventoryd } \\
\hline Frequency & .43 & .24 & .45 & .39 & $.08^{n s}$ & .34 & .52 & .42 & .47 & .47 & .54 \\
\hline Distress & .50 & .28 & .49 & .40 & $.03^{n s}$ & .33 & .60 & .44 & .48 & .51 & .57 \\
\hline Fear of Negative Evaluation ${ }^{2}$ & .63 & .26 & .83 & .16 & .20 & 31 & .64 & .33 & .34 & .73 & .62 \\
\hline Social Desirability: MCSDSc & $-.15^{* *}$ & -.17 & $-.09^{*}$ & $-.04^{\mathrm{ns}}$ & $-.14^{* *}$ & $-.09 *$ & -.18 & -.16 & $-.12^{* *}$ & -.18 & -.18 \\
\hline
\end{tabular}

Notes. For all correlations, $p<.001$ (except as noted). CM = Concern Over Mistakes; HS = High Standards for Others; NA = Need for Approval; OR = Organization; $\mathrm{PP}=$ Perceived Parental Pressure $\mathrm{PL}=$ Planfulness $; \mathrm{RU}=$ Rumination; $\mathrm{SE}=\mathrm{Striving}$ for Excellence $\mathrm{CP}=\mathrm{Conscientious} \mathrm{Perfectionism;} \mathrm{SEP}=$ Self-Evaluative Perfectionism; PI-C = Perfectionism Inventory Composite score; MPS-F = Frost's Multidimensional Perfectionism Scale; MPS-HF = Hewitt and Flett's Multidimensional Perfectionism Scale; BSI = Brief Symptom Index; MCSDS = Marlowe_Crowne Social Desirability Scale.

${ }^{\mathrm{a}} n=613 .{ }^{\mathrm{b}} n=355 . \mathrm{c}_{n}=368 . \mathrm{d}_{n}=207$.

${ }^{*} p<.05$, one-tailed. ${ }^{* *} p<.01$, one-tailed. ${ }^{n s} p>.05$, all one-tailed. 


\section{Method}

\section{Participants and Procedure}

The criterion measures were administered to either all or portions of both exploratory and confirmatory samples described previously along with the $\mathrm{PI}$ items for a possible combined sample of 616 undergraduate students $(M=18.9$ years, $S D=1.7 ; 62 \%$ women, $29 \%$ men, $8 \%$ missing sex; 95\% White, 4\% African American or other race). See Table 6 for specific sample sizes for each of the criterion measures.

\section{Criterion Measures}

MPS-HF. Hewitt and Flett's (1991b) MPS consists of 45 items using a 7-point rating scale ranging from 1 (disagree) to 7 (agree) that comprise three 15-item subscales: SOP, OOP, and SPP. Hewitt, Flett, and colleagues have reported adequate internal consistency, with coefficient alphas ranging from .79 to .89 (Hewitt \& Flett, 1991b), adequate test-retest reliability, and supportive validity evidence (Hewitt \& Flett, 1991a, 1991b; Hewitt et al., 1991a, 1991b). MPS-F. Frost et al.'s (1990) MPS-F consists of 35 items using a 5-point rating scale ranging from 1 (strongly disagree) to 5 (strongly agree) that comprise six subscales: CM, PS, PE, PC, DA, and OR. Frost et al. (1995) have reported adequate internal consistency with coefficient alphas ranging from .77 to .93 , along with substantial evidence for scale validity.

FNE. The brief version of the Fear of Negative Evaluation Scale (FNE; Leary, 1983) is a 12-item self-report measure designed to assess the degree to which people experience apprehension at the prospect of being evaluated negatively (e.g., "I am frequently afraid of other people noticing my shortcomings"). Respondents are asked to rate the degree to which each item is self-descriptive on a 5-point rating scale ranging from 1 (not at all characteristic of me) to 5 (extremely characteristic). Leary reported excellent internal consistency (.90) and test-retest reliability (.75) assessed at a 4-week interval.

BSI. The Brief Symptom Inventory (BSI; Derogatis \& Melisaratos, 1983) is a 53-item, self-report measure comprising nine psychiatric symptom dimensions and a global index of distress. The BSI is a shortened version of the SCL-90 (Derogatis, 1983) designed to measure general psychopathology and psychiatric symptoms. Derogatis reported reliability estimates with alpha coefficients for the nine subscales ranging from .71 on the Psychoticism 
subscale to .85 on the Depression subscale. Derogatis also reported test-retest coefficients ranging from .68 for

somatization to .91 for phobic anxiety. The global severity

index had a stability coefficient of .90 .

$\mathrm{OCl}$. The Obsessive-Compulsive Inventory (OCl; Foa, Kozak, Salkovskis, Coles, \& Amir, 1998) is a self-report instrument designed to describe the presence and severity of obsessive-compulsive disorder symptoms. The $\mathrm{OCl}$ consists of 42 items comprising seven subscales:Washing, Checking, Doubting, Ordering, Obsessing, Hoarding, and Mental Neutralizing. Each item is rated separately for symptom frequency and distress using a 5-point rating scale ranging from 0 (not at all) to 4 (extremely), with larger ratings indicating greater frequency and distress. Composite scores for total $\mathrm{OCl}$ frequency and distress are derived from the seven subscales. Foa et al. reported alpha coefficients ranging from .86 to .95 .

MCSDS. The Marlowe-Crowne Social Desirability Scale (MCSDS; Crowne \& Marlowe, 1960) is a widely used self-report measure consisting of 33 true-false items designed to assess one's need to gain social approval. Crown and Marlowe (1964) reported an internal consistency of .88, and a 1-month, test-retest reliability of .89.

\section{Results}

\section{Convergent Validity With Criterion Measures}

The eight PI scales demonstrated diverse associations with the two MPSs consistent with the respective perfectionism constructs (see Table 6). Among the correlations with other criterion measures, PI Rumination, Concern Over Mistakes, and Need for Approval (the Self-Evaluative aspects of perfectionism measured by the PI) had the highest correlations with theFNEscale. PI Rumination had the highest correlation with $\mathrm{OCl}$ frequency and distress composite scores, followed closely by PI Need for Approval, Concern Over Mistakes, and Striving for Excellence. PI scales were minimally associated with the MCSDS measure of social desirability.

The PI composite scores reflecting the second order factors of Conscientious Perfectionism and Self-Ealuative Perfectionism correlated with MPS criterion measures consistent with the constructs involved (see Table 6). In particular, PI Conscientious Perfectionism was most strongly associated with the MPS-HF SOP and MPS-F PS and OR. PI Self-Evaluative Perfectionism was most strongly associated with MPS-HF SPP and MPS-F CM, 
DA, PC, and PE. PI Conscientious Perfectionism demonstrated low associations with BSI indexes of psychological distress as opposed to the stronger associations between PI Self-Evaluative and BSI indexes, especially the BSI global severity index. PI Self-Evaluative Perfectionism was also more strongly associated with FNE than PI Conscientious Perfectionism. PI Total Perfectionism (sum of all eight scales) was well correlated with all MPS scales, all BSI scales, both $\mathrm{OCl}$ scales, and FNE, as expected.

TABLE 7

Hierarchical Regressions Comparing MPS-HF and MPS-F Scales to PI Scales

\begin{tabular}{llll}
\hline Criterion & Step & $\begin{array}{c}R^{2} \text { Change, MPS } \\
\text { Entered First }\end{array}$ & $\begin{array}{l}R^{2} \text { Change, PI } \\
\text { Entered First }\end{array}$ \\
\hline Fear of Negative & 1 & $.436^{* * *}$ & $.702^{* * *}$ \\
$\quad$ Evaluation & 2 & $.286^{* * *}$ & $.020^{* *}$ \\
BSI-Global & 1 & $.349^{* * *}$ & $.402^{* * *}$ \\
Severity Index & 2 & $.096^{* * *}$ & $.043^{* *}$ \\
BSI-Somatization & 1 & $.175^{* * *}$ & $.151^{* * *}$ \\
BSI-Depression & 2 & .031 & $.055^{* *}$ \\
& 1 & $.249^{* * *}$ & $.300^{* * *}$ \\
BSI-Obsessive- & 2 & $.077^{* * *}$ & .026 \\
Compulsive & 1 & $.321^{* * *}$ & $.282^{* * *}$ \\
BSI-Anxiety & 2 & $.062^{* * *}$ & $.101^{* * *}$ \\
BSI- Interpersonal & 1 & $.255^{* * *}$ & $.268^{* * *}$ \\
Sensitivity & 2 & $.055^{* *}$ & $.042^{*}$ \\
BSI- Hostility & 1 & $.316^{* * *}$ & $.497^{* * *}$ \\
BSI-Phobic & 1 & $.203^{* * *}$ & .023 \\
Anxiety & 2 & $.150^{* * *}$ & $.228^{* * *}$ \\
BSI-Paranoid & 1 & $.093^{* * *}$ & .016 \\
Ideation & 2 & $.220^{* * *}$ & $.209^{* * *}$ \\
BSI-Psychoticism & 1 & $.037^{*}$ & $.048^{*}$ \\
$M$ R & 2 & $.279^{* * *}$ & $.347^{* * *}$ \\
& 1 & $.089^{* * *}$ & .022 \\
\hline Note. Fear & 2 & $.282^{* * *}$ & $.318^{* * *}$ \\
& 1 & $.074^{* * *}$ & $.038^{*}$ \\
& 2 & .276 & .337 \\
& .100 & .039 \\
\hline
\end{tabular}

Note. Fear of Negative Evaluation Scale analyses, $n=613$. Brief Symptom Inventory Scale analyses, $n=368$. MPS-HF $=$ Hewitt and Flett's Multidimensional Perfectionism Scale; MPS-F = Frost's Multidimensional Perfectionism Scale; PI = Perfectionism Inventory; BSI = Brief Symptom Index.

aMPS-HF = Self-Oriented Perfectionism, Other-Oriented Perfectionism, and Socially Prescribed Perfectionism. MPS-F = Concern Over Mistakes, Doubts About Actions, Organization, Parental Criticisms, Parental Expectations, and Personal Standards. PI scales enter in Step 2. bPI = Concern Over Mistakes, High Standards for Others, Need for Approval, Organization, Perceived Parental Pressure, Planfulness, Rumination, and Striving For Excellence. MPS-HF and MPS-F Scales enter in Step 2. ${ }^{*} p<.05 .{ }^{* *} p<.01 .{ }^{* * *} p<.001$. 


\section{Comparison of the Predictive Power of the PI and the MPS Scales}

To examine the relative amounts of information provided by the PI and the MPS scales, a series of hierarchical regression analyses were conducted for criterion variables (the FNE scale and each of the BSI scales). Similar multiple regressions were performed for the $\mathrm{OCl}$, but due to sample size limitations, neither the MPS scales nor the PI accounted for statistically significant proportions of variance (i.e., no statistically significant $R 2$ change statistics).

To examine the degree to which the PI provides information above and beyond the nine MPS scales, we conducted two-step hierarchical regression analyses. In the first step, we predicted a criterion scale from the nine MPS scales. In the second step, we added the eight PI scales as predictors. The change in $R 2$ from the first step to the second step reflects the ability of the PI to predict the criterion variable beyond the MPS scales (see Table 7).

Then, to examine the degree to which the nine MPS scales provide information above and beyond the PI, we conducted similar two-step hierarchical regression analyses. In the first step, we predicted a criterion scale from the PI. In the second step, we added the nine MPS scales as predictors. The change in $R 2$ from the first step to the second step reflects the ability of the MPS scales to predict the criterion variable beyond the $\mathrm{PI}$. We performed these two sets of hierarchical regression analyses (and correlational analyses) separately for the exploratory and confirmatory samples and achieved essentially the same findings.

The results in Table 7 reveal that the PI provides more predictive power than the combined MPS scales. Consider the FNE as an example. The nine MPS scales account for a respectable $44 \%$ of the variance in the FNE, but the PI accounts for fully $29 \%$ additional variance. In contrast, when the PI scales are entered first as predictors of the FNE, they account for $70 \%$ of the variance, and the MPS scales account for only $2 \%$ additional variance. Overall, the PI scales account for more variance in the criterion variables (average $R 2$ when entered first $=.34$ ) than do the MPS scales (average $R 2$ when entered first $=.28$ ). Correspondingly, the average increase in $R 2$ associated with the $\mathrm{PI}$ is .10, which is larger than the average increase in $R 2$ associated with the MPS scales (average increase in $R 2=.04$ ). Furthermore, the PI accounts for more than $5 \%$ extra variance beyond the MPS scales for 9 of the 11 criterion variables. In contrast, the MPS accounts for more than 5\% extra variance beyond the PI scales for only 2 of the 11 criterion variables. 


\section{Discussion}

The PI scales and the second-order PI factors demonstrated correlations with MPS scales consistent with the relevant $\mathrm{PI}$ constructs. PI scale correlations with $\mathrm{FNE}, \mathrm{OCl}$ scales, and the BSI reflected strong associations with convergent PI constructs and weaker correlations with divergent constructs. Hierarchical regression analyses indicated that the PI scales can effectively account for more variance in criterion measures with 59 items than the combined 90 items of the two MPS scales.

\section{GENERAL DISCUSSION}

The PI represents a promising alternative to existing measures of perfectionism. Seeking both inclusiveness and precision, the $\mathrm{PI}$ and its scales are intended to assess the fundamental components of perfectionism with increased efficiency and minimal redundancy. These studies indicate that the PI has strong psychometric properties and predictive power that compares favorably to the commonly used MPS scales.

These studies indicate that the eight PI scales have strong psychometric properties. All PI scales exhibited good variability and clear unidimensional structures, as reflected in exploratory principal components analyses, confirmatory factor analyses, and internal consistency. These properties were consistent across two samples. In addition, the PI scales had high test-retest reliabilities, suggesting that the PI is a stable measure of the underlying constructs.

Although the PI is more efficient than the combined MPS scales, it sacrifices no predictive power. In fact, these analyses demonstrate that the eight PI scales have generally greater predictive ability than the combined nine MPS scales. For the FNE Scale and the 10 scales of the BSI, the PI generally accounted for more variance than the combined MPS scales. Further comparisons of the PI and the MPS scales might reveal particular constructs or general psychological domains that are more strongly predicted by either the PI or the MPS scales, but these analyses do suggest that the PI provides comparably more information related to several fundamental areas of psychological adjustment.

\section{Convergent Validity}

Beyond their psychometric qualities, the PI scales exhibited good convergent validity with other measures of perfectionism and associated constructs. For example, PI Concern Over Mistakes was strongly correlated with MPS-F CM, and PI 
Striving for Excellence was strongly correlated with MPS-F PS and MPS-HF SOP.

PI Planfulness and Rumination reflect unique constructs not clearly conceptually addressed by other MPS scales. The PI Planfulness scale was most strongly associated with MPS-F PS and OR and with MPS-HF SOP scales, consistent with expectations for a scale reflecting planful deliberative tendencies. PI Planfulness was more modestly associated with other MPS scales, suggesting no strong overlap with any particular other MPS construct. PI Rumination was associated most strongly with MPS-F CM, DA, and PS and with MPS-HF SOP and SPP. PI Rumination correlated with MPS scales assessing both evaluative concerns and high standards for performance, supporting the value of PI Rumination as a construct relevant for perfectionism.

Several of the PI scales were associated with indexes of psychological symptoms. Concern Over Mistakes, Need for Approval, and Rumination each had correlations above .50 with the BSI global severity index; the other PI scales each had correlations below 25 with this index of psychopathology. Although these three PI scales showed strong associations with most of the BSI scales, they were most strongly related to BSI Interpersonal Sensitivity. PI Concern Over Mistakes, Need for Approval, and Rumination were also strongly associated with the FNE and the $\mathrm{OCl}$ frequency and distress indexes. Of particular note is that of all the PI scales, Rumination was most strongly correlated with the $\mathrm{OCl}$ indexes, consistent with the persistent obsessive worry common to both constructs.

\section{Higher Order Structure}

In addition to examining each of the eight PI scales independently, we also examined the higher order relationships among the scales and found evidence to support both one-factor and two-factor structures. A one-factor, General Perfectionism modelwas indicated by the exploratory principal components analysis and the high degree of internal consistency among the scales. PI Total Perfectionism was strongly correlated with all of the MPS scales, as well as with the BSI global severity index, $\mathrm{OCI}$ frequency and distress, and FNE, providing support for the convergent validity of the PI. However, a confirmatory factor analysis did not reveal a strong fit for a one-factor model. This suggests that although the PI scales do share much commonality fundamental to perfectionism, there are additional unique relationships among the scales. 
Indeed, previous researchers have suggested that perfectionism constructs often distribute into two basic factors (see Enns \& Cox, 2002; Shafran \& Mansell, 2001). Investigating this possibility, we found evidence for a two-factor, higher order structure among the PI scales, with better (if limited) support from confirmatory fit indexes than the one-factor General Perfectionism model. Conscientious Perfectionism includes Organization, Planfulness, Striving for Excellence, and High Standards for Others. Self-Evaluative Perfectionism includes Rumination, Need for Approval, Concern Over Mistakes, and Parental Pressure. The two factors were highly related to each other, as reflected in their strong positive correlation (see Figure 1) and in the fact that they correlated with some other variables in generally similar directions (see Table 6). Thus, we believe that the labels Conscientious Perfectionism and Self-Evaluative Perfectionism reflect the psychological content of the scales without implying the polarity inherent in the adaptive and maladaptive perfectionism labels that have been suggested by some previous researchers (Cox et al., 2002; Frost et al., 1993; Kawamura et al., 2001; Rheaume, Freeston, et al., 2000; Rice \& Mirzadeh, 2000; Slade \& Owens, 1998; Slaney et al., 2001). PI Self-Evaluative Perfectionism demonstrated a notably higher correlation with the BSI global severity index and FNE than PI Conscientious Perfectionism, consistent with a maladaptive-adaptive interpretation of these factors. However, these two PI factors reflected a mixed array of associations with the MPS scales and with OCI frequency and distress, consistent with the association between the two PI factors.

For many purposes, using the eight PI scales as separate variables might be more fruitful than using either a single General Perfectionism composite or separate Conscientious Perfectionism and Self-Evaluative Perfectionism composites (each derived by summing relevant PI scales). When investigating the relationship between perfectionism and other constructs, the eight PI scale scores may provide a range of psychologically meaningful perfectionism dimensions better than the less discriminating composite second-order factors scores or a single General Perfectionism score.

\section{Future Research}

Future research might investigate the value of the individual $\mathrm{PI}$ scales relative to the composite scales scores when investigating perfectionism. In addition, future research might examine more complex relationships between perfectionism and a broad range of constructs related to personality, psychopathology, and psychological well-being. Although some perfectionism constructs might be positively and linearly 
associated with negative outcomes (e.g., depression, anxiety) and others may be positively and linearly related with positive outcomes (e.g., happiness, well-being), the various perfectionism scales (and even the higher order factors) could be associated nonlinearly with these outcomes. For instance, an individual who experiences too little or too much PI Striving for Excellence may manifest low scores on measures of well-being, achievement, or psychological health, whereas individuals with moderate levels of Striving for Excellence perfectionism may demonstrate higher scores on such measures. Too little Striving for Excellence perfectionism may mean an individual accomplishes little and thus has a reduced basis for a sense of well-being and an increased vulnerability to psychological distress. Too much Striving for Excellence perfectionism may lead an individual to have unrealistic standards for achievement that might result in frequent experience of failure and subsequent psychological distress. Future research might examine a curvilinear relationship between perfectionism and other personality constructs, psychopathology, and psychological well-being.

Interpretations of PI scale scores may be limited by the young age and narrow range of education level and race in the samples. Future investigations using the PI might consider the variability in scale scores found for different age groups. Of particular interest might be the relevance of perfectionistic Parental Pressure for a sample older than the young undergraduates participating in this investigation. Parental Pressure may be more relevant for a younger sample (particularly children or adolescents) than an older sample. In addition, data from clinical samples would assist in assessing the validity of PI scales.

Another direction for future research might be to explore the connections between the PI scales and broader models of personality. For example, the Five-factor model of personality (FFM) is a useful taxonomy of basic personality constructs, and locating new scales or constructs within the FFM space is an advisable step in the assessment process (Ozer \& Reise, 1994). The psychological content of the PI scales indicate that they would be related to at least two of the five factors. In fact, the label for the Conscientious Perfectionism composite was chosen for its conceptual similarity to Conscientiousness from the FFM. Similarly, the Self-evaluative Perfectionism composite has some conceptual overlap with Neuroticism from the FMM. More specifically, researchers could obtain a deeper perspective on the PI and on perfectionism in general by examining the associations between the $\mathrm{PI}$ scales and the facets scores from the Conscientiousness and Neuroticism factors as measured by the NEO-Personality Inventory-Revised (NE-PI-R; Costa \& McCrae, 1992). 
For example, PI scales such as Striving for Excellence, Organization, and Planfulness are likely correlated with

NEO-PI-R Conscientiousness facets of achievement motivation, order, and deliberation, respectively, as was the

MPS-HF SOP scale (Hill, McIntire, \& Bacharach, 1997).

Similarly, PI scales such as Rumination and Concern Over

Mistakes are likely correlated with NEO-PI-R Neuroticism

facets of anxiety and perhaps vulnerability.

In summary, the PI appears to be a useful and relatively efficient measure of perfectionism. In developing the PI, we attempted

to create a measure in which we avoid unnecessary

overlap among scales but in which we preserve, and in fact add, constructs that are fundamental to perfectionism. Although

there are several existing measures that are commonly

used to assess perfectionism, these analyses suggest

that the PI compares quite favorably to these measures in

terms of efficiency, clarity of interpretation, psychometric

quality, and predictive power. We hope that the PI represents

a fruitful contribution to the study of perfectionism. 


\section{REFERENCES}

Antony, M. M., Purdon, C. L., Huta, V., \& Swinson, R. P. (1998). Dimensions of perfectionism across the anxiety disorders. Behaviour Research and Therapy, 36, 1143-1154.

Bastiani, A. M., Rao, R., Weltzin, T., \& Kaye, W. H. (1995). Perfectionism in anorexia nervosa. International Journal of Eating Disorders, 17, 147-152.

Bentler, P. M., \& Wu, E. J. C. (1995). E.Q.S. for Windows users guide. Encino, CA: Multivariate Software.

Blatt, S. (1995). The destructiveness of perfectionism: Implications for the treatment of depression. American Psychologist, 50, 1003-1020.

Bouchard, C., Rheaume, J.,\&Ladouceur, R. (1999). Responsibility and perfectionism in OCD: An experimental study. Behaviour Research and

Therapy, 37, 239-248.

Burns, D. D. (1980, November). The perfectionist's script for self-defeat. Psychology Today, 70-76.

Comrey, A. L., \& Lee, H. B. (1992) A first course in factor analysis (2nd ed.). Hillsdale, NJ: Lawrence Erlbaum Associates, Inc.

Costa, P. T., \& McCrae, R. R. (1992). Revised NEO Personality Inventory (NEO-PI-R) and NEO Five-Factor Inventory (NEO-FFI) professional manual. Odessa, FL: Psychological Assessment Resources.

Cox, B. J., Enns, M. W., \& Clara, I. P. (2002). The multidimensional structure of perfectionism in clinically depressed and college student samples. Psychological Assessment, 14, 365-373.

Crowne, D., \& Marlowe, D. (1960). A new scale of social desirability independent of psychopathology. Journal of Consulting Psychology, 24, 349-354.

Crowne, D., \& Marlowe, D. (1964). The approval motive: Studies in evaluative dependence. New York: Wiley.

Derogatis, L. R. (1983). SCL-90-R administration, scoring, and procedures manual-II. Towson, MD: Clinical Psychometric.

Derogatis, L. (1993). BSI-Brief Symptom Inventory: Administration, scoring, and procedures manual. Minneapolis, MN: National Computer Systems.

Derogatis, L. R., \& Melisaratos, N. (1983). The Brief Symptom Inventory: An introductory report. Psychological Medicine, 13, 595-605. 
Enns, M. W., \& Cox, B. J. (1999). Perfectionism and depression symptom severity in major depressive disorder. Behaviour Research and Therapy, 37, 783-794.

Enns, M.W., \& Cox, B. J. (2002). The nature and assessment of perfectionism: Acritical analysis. In G. L. Flett\&P. L. Hewitt (Eds.), Perfectionism: Theory, research and practice (pp. 33-62). Washington, DC: American Psychological Association.

Flett, G. L., Hewitt, P. L., Blankstein, K. R., \& Gray, L. (1998). Psychological distress and the frequency of perfectionistic thinking. Journal of Personality and Social Psychology, 75, 1363-1381.

Flett, G. L., Hewitt, P. L.,\&Derosa, T. (1996). Dimensions of perfectionism, psychosocial adjustment, and social skills. Personality and Individual Differences, 20, 143-150.

Flett, G. L., Hewitt, P. L., Endler, N. S., \& Tassone, C. (1995). Perfectionism and components of state and trait anxiety. Current Psychology, 13, 326-350.

Flett, G. L., Sawatzky, D. L., \& Hewitt, P. L. (1995). Dimensions of perfectionism and goal commitment: A further comparison of two perfectionism measures. Journal of Psychopathology and Behavioral Assessment, 17, 111-124.

Foa, E. B., Kozak, M. J., Salkovskis, P. M., Coles, M. E., \& Amir, N. (1998). The validation of a new obsessive-compulsive disorder scale: The ObsessiveCompulsive Inventory. Psychological Assessment, 10, 206-214.

Frost, R. O., Heimberg, R. G., Holt, C. S., Mattia, J. I., \& Neubauer, A. L. (1993). A comparison of two measures of perfectionism. Personality and Individual Differences, 14, 119-126.

Frost, R. O., Marten, P., Lahart, C., \& Rosenblate, R. (1990). The dimensions of perfectionism. Cognitive Therapy and Research, 14, 449-468.

Frost, R. O., \& Steketee, G. (1997). Perfectionism in obsessive compulsive disorder patients. Behaviour Research and Therapy, 35, 291-296.

Frost, R. O., Turcotte, T. A., Heimberg, R. G., Mattia, J. I., Holt, C. S., \& Hope, D. A. (1995). Reactions to mistakes among subjects high and low in perfectionistic concern over mistakes. Cognitive Therapy and Research, 19, 195-205.

Hamachek, D. E. (1978). Psychodynamics of normal and neurotic perfectionism. Psychology: A Journal of Human Behavior, 15, 27-33.

Hewitt, P. L., \& Flett, G. L. (1991a). Dimensions of perfectionism in unipolar depression. Journal of Abnormal Psychology, 100, 98-101. 
Hewitt, P. L., \& Flett, G. L. (1991b). Perfection in the self and social contexts: Conceptualization, assessment, and association with psychopathology. Journal of Personality and Social Psychology, 60, 456-470.

Hewitt, P. L., Flett, G. L., \& Turnbull-Donovan, W. (1992). Perfectionism and suicide potential. British Journal of Clinical Psychology, 31, 181-190.

Hewitt, P. L., Flett, G. L., Turnbull-Donovan,W.,\&Mikail, S. F. (1991). The Multidimensional Perfectionism Scale: Reliability, validity, and psychometric properties in psychiatric samples. Psychological Assessment, 3, 464-468.

Hewitt, P. L., Mittelstaedt,W.,\&Wollert, R. (1989). Validation of a measure of perfectionism. Journal of Personality Assessment, 53, 133-144.

Hill, R. W., McIntire, K., \& Bacharach, V. (1997). Perfectionism and the big five factors. Journal of Social Behavior and Personality, 12, 257-270.

Hill, R. W., Zrull, M. C., \& Turlington, S. (1997). Perfectionism and interpersonal problems. Journal of Personality Assessment, 69, 81-103.

Hu, L., \& Bentler, P. M. (1999). Cutoff criteria for fit indexes in covariance structure analysis: Conventional criteria versus new alternatives. Structural Equation Modeling, 6, 1-55.

Johnson, D. P., \& Slaney, R. B. (1996). Perfectionism: Scale development and a study of perfectionistic clients in counseling. Journal of College Student Development, 37, 29-41.

Kawamura, K. Y., Frost, R. O., \& Harmatz, M. G. (2002). The relationship of perceived parenting styles to perfectionism. Personality and Individual Differences, 32, 317-327.

Kawamura, K. Y., Hunt, S. L., Frost, R. O., \& Dibartolo, P. (2001). Perfectionism, anxiety, and depression: Are the relationships independent? Cognitive Therapy and Research, 25, 291-301.

Kennedy, C. (2001). Comprehensive Measure of Perfectionism. Unpublished master's thesis, Appalachian State University, Boone, NC.

Leary, M. R. (1983). A brief version of the Fear of Negative Evaluation Scale. Personality and Social Psychology Bulletin, 9, 371-375.

Nilsson, J. E., Paul, B. D., Lupini, L. N., \& Tatem, B. (1999). Cultural differences in perfectionism: A comparison of African American and White college students. Journal of College Student Development, 40, 141-150. 
Ozer, D. J., \& Reise, S. P. (1994). Personality assessment. Annual Review of Psychology, 45, 357-388.

Purdon, C., Antony, M., \& Swinson, R. (1999). Psychometric properties of the Frost Multidimensional Perfectionism Scale in a clinical anxiety disorders sample. Journal of Clinical Psychology, 55, 1271-1286.

Rheaume, J., Freeston, M. H., Dugas, M. J., Letarte, H., \& Ladouceur, R. (1995). Perfectionism, responsibility and obsessive-compulsive symptoms. Behaviour Research and Therapy, 33, 785-794.

Rheaume, J., Freeston, M. H., Ladouceur, R., Bouchard, C., Gallant, L., Talbot, F., et al. (2000). Functional and dysfunctional perfectionists: Are they different on compulsive-like behaviors? Behaviour Research and Therapy, 38, 119-128.

Rheaume, J., Ladouceur, R., \& Freeston, M. H. (1995). Inflated responsibility in obsessive-compulsive disorder: Validation of an operational definition. Behaviour Research and Therapy, 33, 159-169.

Rheaume, J., Ladouceur, R.,\&Freeston, M. H. (2000). The prediction of obsessivecompulsive tendencies: Does perfectionism play a significant role? Personality and Individual Differences, 28, 583-592.

Rice, K. G., Ashby, J. S., \& Slaney, R. B. (1998). Self-esteem as a mediator between perfectionism and depression: A structural equation analysis. Journal of Counseling Psychology, 45, 304-314.

Rice, K.G., \& Mirzadeh, S. A. (2000). Perfectionism, attachment, and adjustment. Journal of Counseling Psychology, 47, 238-250.

Shafran, R., \& Mansell, W. (2001). Perfectionism and psychopathology: A review of research and treatment. Clinical Psychology Review, 21, 879-906.

Slade, P. D., \& Owens, R. G. (1998). A dual process model of perfectionism based on reinforcement theory. Behavioral Modification, 22, 372-390.

Slaney, R. B., Rice, K. G., Mobley, M., Trippi, J., \& Ashby, J. S. (2001). The revised Almost Perfect Scale. Measurement and Evaluation in Counseling and Development, 34, 130-146.

Stober, J. (1998). The Frost Multidimensional Perfectionism Scale revisited: More perfect with four (instead of six) dimensions. Personality and Individual Differences, 24, 481-491.

Stumpf, H., \& Parker, W. (2000). A hierarchical structural analysis of perfectionism and its relation to other personality characteristics. Personality and Individual Differences, 28, 837-852. 